\title{
Novas visións socioliterarias da saudade: a súa desmitificación e crítica na obra de Seoane, Valente e Rivas
}

\author{
Antía Fernández Martínez ${ }^{1}$
}

Recibido: 15 de xuño de 2019 / Aceptado: 25 de marzo de 2020

Resumo. Este artigo presenta un breve percorrido cronolóxico pola literatura galega dende mediados do século XX ata a actualidade, personificado nas figuras de Luís Seoane, José Ángel Valente e Manuel Rivas, para analizar como neles o discurso tradicional da saudade é dinamitado creando novas concepcións para o termo, concepcións que abarcan maiores territorios e identidades e que restrinxen moito menos non só a idea de Galicia, senón tamén a nosa idea de nós mesmos.

Palabras chave: saudade; morriña; emigración; crítica; desmitificación; desterritorialización.

\section{[es] Nuevas visiones socioliterarias de la saudade: su desmitificación y crítica en la obra de Seoane, Valente y Rivas}

Resumen. Este artículo presenta un breve recorrido cronológico por la literatura gallega desde mediados del siglo XX hasta la actualidad, personificado en las figuras de Luís Seoane, José Ángel Valente y Manuel Rivas, para analizar cómo en ellos el discurso tradicional de la saudade es dinamitado creando nuevas concepciones para el término, concepciones que abarcan mayores territorios e identidades y que restringen mucho menos no solo la idea de Galicia, sino también nuestra idea de nosotros mismos.

Palabras clave: saudade; morriña; emigración; crítica; desmitificación; desterritorialización.

\section{[en] New Socioliterary Visions of Saudade: Demystification and Criticism in the Work of Seoane, Valente and Rivas}

\begin{abstract}
This article presents a brief chronological journey through Galician literature from the mid-twentieth century to the present, personified in the figures of Luís Seoane, José Ángel Valente and Manuel Rivas, in order to analyze how the traditional discourse of saudade is dynamited in their work, creating new conceptions for the term that encompass bigger territories and identities and that restrict much less not only the idea of Galicia, but also our idea of ourselves.

Keywords: Saudade; Morriña (Homesickness); Emigration; Criticism; Demystification; Deterritorialization.

Sumario. 1. Introdución. 2. Breves e imprescindibles apuntes sobre a saudade e a súa evolución histórica e literaria. 2.1. Ramón Piñeiro, unha filosofía da saudade e a Galicia rosaliana. 3. Luís Seoane cargando o fardel da emigración. 3.1. "No se puede continuar hablando de saudade...". 4. José Ángel Valente, ou a pertenza ao non-lugar. 4.1. A emigración como decisión persoal. 4.2. A saudade das cántigas. 5. Manuel Rivas e a súa Galicia 2.0: a identidade na era da globalización. 5.1. Galicia emigrante. 5.2. A saudade en Manuel Rivas. 6. Conclusións. 7. Referencias bibliográficas.
\end{abstract}

Como citar: Fernández Martínez, A. (2020): "Novas visións socioliterarias da saudade: a súa desmitificación e crítica na obra de Seoane, Valente e Rivas”, en Madrygal. Revista de Estudios Gallegos 23 Núm. Especial, pp. 123-139

1 Universidade de Santiago de Compostela. Departamento de Lingua e Literatura Españolas, Teoría da Literatura e Lingüística Xeral.

Correo-e: antiafermar@gmail.com; https://orcid.org/0000-0002-0383-4188. 


\section{Introdución}

Hai un tempo publicamos no número 20 de Madrygal un artigo titulado "Nacionalismo, saudade, mito e historia en Fernando Pessoa y Luís Seoane" no que explorabamos como na obra do portugués Fernando Pessoa e na do galego-arxentino Luís Seoane confluían a visión crítica sobre a construción do discurso nacional (portugués e galego, respectivamente) e o proceso de desmitificación romántica da saudade. Debido a iso as similitudes entre o referido traballo e a primeira parte deste, o apartado dedicado de novo a Luís Seoane, deben ser aquilatadas, xa que ambos parten do mesmo traballo de investigación. O presente artigo vén a constituír, dalgún xeito, unha continuación daquel, unha actualización do tema dende unha perspectiva máis próxima no tempo, traducíndose nunha viaxe cronolóxica e literaria dende os comezos do século XX ata os nosos días.

O que presentamos nesta ocasión é unha aproximación a tres escritores galegos dos séculos XX e XXI (Luís Seoane, José Ángel Valente e Manuel Rivas) e como neles son actualizados os motivos literarios e socioculturais asociados ao sentimento saudadoso na súa vertente máis fecunda na literatura e no imaxinario galego, a aquí denominada saudade morriñenta ou saudade da terra.

Así, as páxinas que seguen constitúen tamén, a través da visión que os autores fixeron da saudade, un acercamento a tres modos diferentes, literarios e ideolóxicos, de responder á realidade social e cultural galega, á súa historia migratoria e ás implicacións sociais e artísticas que esta trae consigo, dende a crítica económica, á territorial e á política.

\section{Breves e imprescindibles apuntes sobre a saudade e a súa evolución histórica e literaria}

\subsection{Ramón Piñeiro, unha filosofía da sauda- de e a Galicia rosaliana}

A procura dunha definición certeira para a palabra saudade sempre foi motivo de polémica, e centos e centos de follas escribíronse buscando a descrición máis precisa posible. Tras moitas análises etimolóxicas, literarias, sociais e históricas, e despois de preto de dous séculos de discusión arredor do tema, o termo segue suscitando controversia, inda que seguramente menos que naquela época na que a construción nacional de Portugal ou de Galicia se atopaba dando os seus primeiros pasos, e verbas como as que agora nos ocupan era tomadas como emblemas nacionalistas.

Dentro do ámbito galego, Ramón Piñeiro foi o máis destacado e importante estudoso teórico da saudade, e dada a influencia que os seus traballos terían nos intelectuais galegos posteriores é importante realizar un breve achegamento á súa figura. O pensamento e obra dos tres escritores que se analizan aquí son tres propostas ideolóxicas que, directa ou indirectamente, contestan e se opoñen frontalmente ás teorías de Piñeiro.

Ramón Piñeiro (1915-1990), intelectual e político, publicou en 1983 unha obra capital para entender a cultura galega do século XX, a súa Filosofia da saudade, un compendio de catro ensaios sobre a saudade que o autor fora publicando a partir dos anos 50 e nos que profunda na dimensión ontolóxica do sentimento. Figura clave do galeguismo e firme defensor da idea de que era a través da cultura como Galicia tiña que ser defendida, protexida e fomentada a súa forma de vida (dando lugar á corrente ideolóxica denominada piñeirismo) (Miguélez-Carballeira 2014: 222), Piñeiro entendeu a saudade no seu estado puro como un sentimento provocado polo contacto do individuo coa súa máis pura intimidade (Piñeiro 2001: 38). Segundo esta visión, cando o suxeito toma contacto consigo mesmo, co seu eu interior, descobre a súa singularidade ontolóxica, e, por conseguinte, a súa soidade: "A Saudade é, pois, o sentimento da soidade ontolóxica do home" (Ibid.: 42). Pero, ademais, a saudade viría a ser tamén a experiencia humana que mellor recolle o peculiar matiz de sentimentalismo que caracterizaría o pobo galaico-portugués (Piñeiro 2001: 28).

Coa súa filosofía da saudade, Ramón Piñeiro pretendía crear un sistema filosófico e ontolóxico propio e particular do noroeste, sistema entendido como "unha peculiar actitude mental ou interpretación dos problemas filosóficos, ou mellor, nunha peculiar vivencia e expresión destes problemas" (Ibid.: 26). Grazas a este sistema, defendía Piñeiro, Galicia ${ }^{2}$, que ata entón

\footnotetext{
En realidade, o sistema deseñado por Ramón Piñeiro diríxese ao pobo luso-galaico. O proxecto de Piñeiro é, en todo momento, un proxecto compartido con Portugal: "a saudade é un trazo común á espiritualidade galega e mais á portuguesa; é, poderiamos dicir, un producto cultural que comparten Galicia e Portugal” (2001: 98).
} 
se atopaba orfa dunha filosofía propia, dotaríase dunha forma propia de pensamento que a axudaría no seu desenvolvemento cultural e espiritual: "Só así, tendo conciencia da nosa personalidade verdadeira, poderemos seguir sendo un pobo. De non termos esa conciencia, quedaremos reducidos á simple condición de país habitado" (Ibid.: 94). É dicir, e destacando aqueles elementos da súa teoría que máis nos interesan para a nosa análise, o que fai Ramón Piñeiro no devandito traballo é apelar ao sentimentalismo como elemento configurador do pobo galego, algo, pola outra banda, bastante frecuente nos galeguistas da época. Frecuente tamén era esta apelación ao referido sentimentalismo con fins nacionalistas (Miguélez-Carballeira 2001: 104-107), así como a identificación da poetisa Rosalía de Castro co referido sentimentalismo, tal como fai Ramón Piñeiro no derradeiro dos ensaios que compoñen o seu libro, "A saudade en Rosalía", traballo publicado orixinalmente en 1952 dentro do volume Sete ensaios sobre Rosalía.

Inda que Rosalía de Castro foi xa dende a publicación dos seus primeiros traballos unha figura fundamental das letras galegas, entre os años 50 e 60, a través de Ramón Piñeiro e dos intelectuais vinculados ao proxecto de Galaxia e ao piñeirismo, prodúcese unha revalorización e revalidación, por unha banda, da figura da poetisa como símbolo nacional e, pola outra, da súa poesía como máxima expresión da alma galega, neutralizando a súa condición humana e feminina, desexualizándoa e converténdoa en "metáfora nacional", en corpo feito espírito da propia Galicia, na voz do pobo, ao mesmo tempo que se procuraba a universalización da súa obra (Miguélez-Carballeira 2014: 197, 246). Para Ramón Piñeiro Galicia chegárase a identificar coa imaxe que dela creara Rosalía, unha imaxe "tristeira" e "exaltada" (Piñeiro 2001: 121), é dicir, producírase unha identificación moral entre Galicia e o sentir de Rosalía (Ibid.: 126). Porén, é importante apuntar a distinción que Piñeiro realiza entre a referida imaxe rosaliana de Galicia e a propia Galicia, xa que, pese a que concibe a alma galega como unha alma sentimental, non considera este sentimentalismo nos termos de melancolía e de dor, termos que si aplica a Rosalía: "A alma galega é sentimental, mais non é dorida. Non ama nin busca a dor [...] Busca sempre o sentimento, a vivencia sentimental, o intimismo subxectivo, se se quere. Mais esta maneira de sentir, que é peculiar da alma galega, non hai que a confundir co sentimento da dor, que é peculiar de Rosalía" (Ibid.: 127). A identificación entre Galicia, saudade e Rosalía de Castro, entendidos como tres entes indisolubles dunha mesma realidade, non foi tan só produto dos traballos de Piñeiro e dos seus seguidores, pero si que constituíron unha pedra angular na implantación popular do referido imaxinario. $E$ inda que non temos espazo neste momento para analizalo, as relecturas da saudade presentadas a continuación implicaron tamén a relectura da figura de Rosalía de Castro. Esta, progresivamente, e en tanto en canto entendida como "personificación galega" da saudade, verase afectada por estas reinterpretacións, enfatizándose progresivamente os aspectos máis subversivos e rebeldes da súa obra en vez da tradicional lectura melancólica.

\section{2. Á procura dunha definición da saudade}

Tras e a pesar de tantas polémicas e ríos de tinta, poderiamos aproximarnos a unha primeira e básica definición da saudade falando dela como a manifestación dun sentimento causado por unha ausencia na súa dimensión temporal. Ben é certo que o termo ausencia xa contén en si mesmo a referencia temporal, xa que unicamente podemos estrañar no presente aquilo do que tivemos coñecemento ou vivencia nalgunha ocasión pasada, pero levaríanos aquí demasiadas páxinas discernir a diferenza entre o sentimento saudoso e outros próximos a el como poden ser a melancolía ou a nostalxia. Non é, por tanto, este o lugar para debater sobre o asunto, xa que, ao noso parecer, a maior diferenza entre eles non recae tanto no compoñente vivencial ou psicolóxico de cada un destes sentimentos, senón no proceso de configuración literaria, social e nacional de cada un dos termos, é dicir, do imaxinario creado arredor de cada un deles, ao proceso de asociación dun sentimento (o que, como tal, non pode ser máis que universal e común a todos os seres humanos) a unha serie de características particulares, xa sexan dun territorio, dunha cultura particular, dunha lingua, ou dunha época concreta.

Dentro desta definición ampla do termo, moitos e diferentes tipos de ausencias e de saudades caben nela: dende a saudade do namorado ou namorada tan profusa na literatura portuguesa á saudade da patria perdida. No presente estudo, ímonos referir tan só á saudade na súa vertente de saudade da terra, por ser esta a forma baixo a cal a saudade foi maioritariamente desenvolvida na literatura galega: "En la literatura gallega, escrita dentro y 
fuera de Galicia, este capítulo de las saudades nostálgicas es interminable y ocupa un lugar preminente" (Landeira 1970: 71), polo que á hora de falar desta forma de saudade e antes de analizar con máis detalle os autores escollidos, é inevitable pararnos a reflexionar sobre a diferenza que hai, ou pode haber, entre esta forma de sentir saudoso e a morriña, forma moito máis popular ou coloquial de referirse a este tipo de dolor pola ausencia.

Para Ramón Piñeiro, a morriña non é senón a "resonancia psicolóxica da saudade", é dicir, a denominación dada ao estado de "tristura vaga" que provoca a vivencia da soidade (2007: 45). Pola súa parte, Cabanillas entende a morriña como a saudade da terra "fisicamente doorosa" (2000: 21). Carolina Michaëlis interpreta o termo tanto como un "vulgarismo" dos trobadores galaico-portugueses, unha forma deformada da palabra saudade (2016: 34), como a forma dada en Galicia para nomear á saudade (Ibid.: 72); e Castelao definíaa como un "estado especial", consciente, da saudade: "A Morriña, pois, é a Saudade en estado de concencia" (1977: 355). Tamén é destacable a etimoloxía que dá Xesús Alonso Montero ao respecto, para quen ambos termos, saudade e morriña, posúen un alto grao de equivalencia, inda que posteriormente matizara como nas últimas décadas (é dicir, dende mediados do século XX) os "utilizadores rigurosos del idioma", entre os que destaca Ramón Piñeiro, matizaron a distinción entre un termo e o outro:

Aunque los etimólogos andan a la greña, hay que relacionarla muy directamente con el infinitivo «morrer» (morir), lo que nos obliga a pensar que morriña es una especie de muerte pequeña que siente en sus entrañas el que está privado de algo muy importante, ya la patria, ya la amada, ya cualquier otra realidad de este rango. A veces, poetas y prosistas gallegos utilizan como sinónimo de morriña los siguientes términos: «saudade», «soidade», «soedade» y «señardade». (Alonso Montero 1972: 65-66)

Pola súa parte, Torres Queiruga identifica a saudade da terra e a da persoa amada como os dous modos fundamentais da saudade. Mentres 'nostalxia' sería a palabra utilizada para referirse á primeira destas formas (1980: 23), 'morriña' sería o termo tomado para aludir ao sentimento destes dous modos de saudade vivenciándose á vez. É dicir, para este autor a morriña é a ausencia conxunta da terra e dos seres queridos, a vivencia simultánea destas dúas formas de saudade (Ibid.: 23).

Seguindo dalgún xeito esta estela teórica, para Ramón Piñeiro a maioría dos poetas e dos teóricos que se aproximaron ao problema da saudade -tales como Ramón Cabanillas, Vicente Risco, Xohan V. Viqueira, R. Novoa Santos ou Plácido R. Castro-identificaban, na maioría das ocasións, a saudade co sentimento de nostalxia cara á terra, debido, segundo o seu parecer, ao feito de ser esta a forma de expresión dominante na poesía popular e na cultura galegas, alentada, ademais, polo fenómeno da emigración (Piñeiro 2007: 111). Deste modo, podemos deducir que en moitas ocasións na literatura galega, e especialmente na cultura e no sentir popular, a saudade e a morriña tomáronse como sinónimos, sen ter en conta outras posibles formas de saudade e coa diferenza de que o desenvolvemento e armazón teórico que tivo o termo saudade non o tiveron outras palabras como morriña, entendida esta como unha forma concreta e simplificada nas súas connotacións da saudade.

A saudade da terra, ou morriña ${ }^{3}$, como prefiramos denominala, é, como diciamos, a forma máis típica e desenvolvida da saudade na tradición literaria galega. Este modo de saudade aparece moi axiña nos autores do Rexurdimento, e incluso naqueles denominados precursores, como Nicomedes Pastor Díaz (1811-1863), entre outros (Landeira 1970: 57). Torres Queiruga sinalaba como na morriña conflúen a saudade da terra e a saudade do ser amado, circunstancia que, apunta, se dá normalmente na emigración (1980: 23). Certamente en Galicia a saudade da terra encóntrase moi ligada á historia da emigración e do exilio do seu pobo, como deixou plasmado Rosalía de Castro en poemas como "Adiós ríos, adiós fontes" ou "Airiños, airiños aires", de tanto calado no imaxinario compartido galego. Tamén foi a saudade da emigración o tema que máis interesou a Curros Enríquez (Ibid.: 152) e que deixaría fixada en poemas como "Cántiga", do seu poemario Aires da miña terra", onde a saudade polo amor perdido ou ausente se mestura coa saudade da terra, conformando

\footnotetext{
3 "Sempre, naturalmente, que, de acordo polo demais cun uso moi extendido, a liberemos das connotacións pexorativas de depresión e pasividade" (Torres Queiruga 1980: 23).

4 A referencia no título a Rosalía e a súa poesía sobre a emigración é clara e directa.
} 
a saudade do emigrado ${ }^{5}$, a morriña tal como era denominada por Torres Queiruga. Esta é a configuración da saudade que, como veremos, tamén se reflicte nos autores que analizaremos a continuación.

\section{Luís Seoane cargando o fardel da emi- gración}

Luís Seoane (1910-1979) é unha das personalidades do século XX que mellor encarnan e representan tanto a historia migratoria galega a América como o exilio exterior que supuxo a guerra civil española e a posterior longa noite da ditadura franquista. Fillo de emigrantes galegos na Arxentina, onde naceu, con seis anos volve a Galicia, que terá que deixar en 1936 por mor do estalido da guerra civil, xa que dende os anos de estudante se involucrara activamente no ambiente político e cultural galego, adheríndose ao pensamento galeguista e marxista. Tanto artística como biograficamente, Luís Seoane estivo sempre a cabalo entre América e Galicia, tanto física como emocionalmente, o que dota a súa obra dunha interesantísima perspectiva vital á hora de abordar o motivo literario da saudade

Ao compoñente biográfico, temos de sumarlle o ideolóxico, factor sen o cal calquera análise da obra de Seoane irremediablemente resulta limitada. Marxista e galeguista, durante os seus anos de exilio en América, Seoane estará á fronte de grande parte das iniciativas culturais da Galicia do exterior, tales como as revistas Galicia libre, Galicia emigrante ou Cuco-Rei, a editorial Citania ou, xunto a Isaac Díaz Pardo, o Laboratorio de Formas de Galicia, xerme do que será o complexo de Sargadelos. Igualmente, realizou debuxos e gravados para grande parte da literatura galega que estaba sendo publicada en América ante a imposibilidade de facelo na propia terra a causa da ditadura. Non só na súa obra literaria, menos coñecida, senón tamén a través da pintura criticará a crúa realidade da emigración e a precariedade das capas más baixas da sociedade en obras como Emigrante (1967), Cristo obrero crucificado (1975) ou Mariscadoras (1964/1969).
Fronte ao "nacionalismo de interior" de Piñeiro, unidireccional cara a Europa e defensor dunha ortodoxa identidade, Seoane propoñerá un nacionalismo aberto, que mira cara a América e busca os elementos de interculturalidade e hibridación que a emigración leva e trae consigo $^{6}$ (Fernández Martínez 2017).

\section{1. "No se puede continuar hablando de saudade..."}

Como apuntabamos brevemente, Luís Seoane foi unha personalidade de fortes conviccións políticas e á hora de analizalo como creador, ben sexa na súa faceta de pintor, ben na de escritor, non podemos separar a súa obra do seu pensamento.

Luís Seoane publica en 1952 en Bos Aires un poemario titulado Fardel de eisilado. O libro ábrese cunha 'Adicatoria e crida' que xa supón unha verdadeira declaración de intencións dos fins que persegue o autor coa escritura e publicación do seu libro: a dignificación do pobo galego e a reescritura da súa historia dende a colectividade, facéndose eco da odisea da emigración galega: "o verdadeiro héroe de Galicia foi sempre o povo galego [...] E os homes xurdidos dese povo [...] son en derradeiro termo os heroes, e non os famosos Condes do século XV como, ó xeito romántico, tratou de facernos creer unha historia de abondo aristocratizante" (Seoane 2002: 12). Ao destacar o carácter colectivo da historia galega e, ademais, ao indicarnos como "o seu pulo económico xurdiu sempre da necesidade económica" (Ibid.: 12), o pintor e escritor non agocha a motivación política, de corte marxista, que alenta a escritura do Fardel: "desexando continuar sendo, como fun deica agora pintando e escribindo un peón máis [...] na laboura coleitiva polo rexurdimento da cultura galega" (Ibid.: 13). Inaugura así Seoane unha nova forma de crítica: "Foi o iniciador en 1952 da poesía de intención política nacional e antifeixista en Galicia" (Méndez Ferrín 2011: 348), precedendo en dez anos ao que será considerado o gran poemario civil da literatura galega, a Longa noite de pedra de Celso Emilio Ferreiro (Alonso Montero 2002: 77).

\footnotetext{
5 "Noites craras, de aromas e lúa, / desde entón ¡qué tristeza en vós hai / prós que viron chorar unha nena, / prós que viron un barco marchar!..." (vv. 27-30).

6 Para máis referencias e bibliografía acerca da oposición ideolóxica Piñeiro/Seoane, remitimos ao noso mencionado artigo (Fernández Martínez 2017).
} 
Deste xeito, o que logra Seoane en Fardel de esilado é, a través da presentación de diferentes momentos históricos e destinos da emigración galega ao longo de dous séculos (dende a de Ramón Cernadas no século XVIII ata a súa propia e a dos seus contemporáneos no século XX) promover "unha comprensión da emigración como constante histórica" (Casas 2010: 18), a pesar de que a masa social, entendida esta como o conxunto de cidadáns ou grupo que comparte unhas vivencias (opresións) políticas, económicas e sociais comúns, inda estando insinuada, non chega a manifestarse como suxeito político (Ibid.: 18). Podemos intuír, entón, que dadas estas premisas ideolóxicas e de análise histórica, a saudade presentada por Seoane no seu poemario estará lonxe da visión romántica e utilitarista desta.

A saudade dos emigrantes do Fardel relaciónase cun motivo moi presente na literatura sobre o tema: a recreación da paisaxe perdida. No primeiro poema do poemario, titulado "O pintor eisilado", título cun claro matiz autobiográfico, o eu poético recorda a paisaxe da terra distante, a súa natureza, a súa luz e as súas cores (a paisaxe visual), e recréase neles na distancia:

Ao pintar lembran seus ollos ensimesmados o ar gris [da lonxana montaña

o vento norte marmuriador cor de aceiro, as formas [das uces marteiradas, a braña,

as boullosas verdes carballeiras, os ríos, as lombas [azures encostadas

(“O pintor eisilado", vv. 1-3)

Poñamos atención ao primeiro verso do poema, no que se produce unha importante personificación: son os ollos do pintor os que lembran e non o pintor. Estes recordan sobre todo as cores, as sensacións producidas pola paisaxe deixada atrás: o ar gris, o vento cor de aceiro, as verdes carballeiras, as azuis lombas, as terras ocres ou negras, etc. A capacidade de lembrar a través da mirada é a que lle permite ao pintor exiliado a reprodución no lenzo da paisaxe evocada. A través do recordo, o pintor pode "ver" o que quere pintar: "Cando caviloso vai lixando co pincel a branca tea de liño / ó seu acordo veñen as cores rosas da nenez, o risco solermiño" (vv. 9-10). É esta unha importante facultade da saudade, como veremos posteriormente con máis detalle ao analizar a poesía de José Ángel Valente: a oportunidade de, a través da memoria, facer presente o ausente.

Tamén é importante sinalar a asociación de cores que o pintor realiza, obviamente modificados polo recordo. Son as cores do sentimento, das sensacións, e non as cores da natureza, dado que o aire pode ser gris, o vento da cor do aceiro, as lombas azuis ou rosas as lembranzas da infancia, non porque sexan as cores que presentan na realidade, senón porque son os tons que nel debuxan os recordos.

Porén, a saudade da terra fai presente non só a paisaxe deixada atrás, senón tamén os seres queridos que un non sabe cando volverá ver:

\section{Vexo como estadeas percorrer polo ar, en ringleiras, aos parentes próisimos, aos amigos queridos, mortos, ou si vivos, somidos en espesas, mouras tebras, e acarón deles sinto que se xunguiron pra sempre a miña vida pasada, o meu presente vivo e o meu porvir. \\ ("Dende o Highland Princess", vv. 17-21)}

Voz individual e voz colectiva que se converten nunha soa. Atopámonos agora, avanzando no poemario, ante o testemuño dun emigrante anónimo que, dende o barco que o leva a América, ve desaparecer na distancia a costa galega e reflexiona sobre todo o que deixa atrás. Un emigrante máis, como tantos -quizais o propio Seoane-, pero no que, ao mesmo tempo, moitas voces poden ser recoñecidas. Eses "amigos queridos, mortos, / ou si vivos, somidos en espesas, mouras tebras" non son unicamente os amigos concretos do emigrante, senón tamén todos os galegos, e por extensión, todos os seres humanos, mortos na guerra ou condenados ao exilio, interior ou exterior. $\mathrm{O}$ emigrado continúa reflexionando sobre todos estes "amigos", facendo a colectividade á que se refire incluso máis patente:

Ises mortos tecerán no seu corazón, coma nós, xenerosas espranzas pra tódolos homes, novos [pensamentos,

o mesmo que aqueles que, condanados ao silenzo, aínda viven esquecidos nas túas témeras cárceres, agachados coma alimañas nas covas sobrosas dos [montes

ou atobados, arredrados de si mesmos, polas [afastadas rúas.

("Dende o Highland Princess", vv. 22-27)

O ton autobiográfico deste poema é tamén elevado, xa que "Highland Princess" é o nome real do navío no que Luís Seoane embarcou para viaxar dende Galicia a Bos Aires tras o inicio da guerra civil; é dicir, é o nome real do barco que o levou ao exilio (Alonso Montero 2002: 78). 
Unha palabra destaca nestes versos sobre todas as demais: esperanzas (v. 23), xa que, en poemas como estes, a saudade da terra (saudade presentida, que non vivida inda, xa que o emigrante estase aínda afastando da costa natal) acábase convertendo en saudade da ra$\mathrm{za}$, forma de saudade que aparece ao converxer a saudade da terra coa mensaxe política anteriormente analizada. Pero, curiosamente, e a diferenza doutros enfoques literarios, é esta unha saudade que se proxecta tan só cara ao futuro, apenas cara ao pasado: non hai un pasado glorioso que anhelar. Os únicos episodios históricos aos que alude Seoane son os da emigración galega das capas máis populares da poboación (a colonización galega do século XVIII, a construción da ponte de Brooklyn durante o século XIX), pero non as dun célebre pasado perdido, real ou metafórico, que deba ser recuperado. É o recordo do país que queda atrás o que consegue espertar a esperanza, a proxección dun futuro mellor grazas á unión dos emigrados, non a dun pasado cobizado:

$\begin{aligned} & \text { Doorido, dende o combés deste barco, véxote } \\ & \text { [debruzada ao mar. }\end{aligned}$
$\begin{aligned} & \text { Mais un día voltarei, derrubado e a vez afirmado } \\ & \text { [polo tempo, }\end{aligned}$
$\begin{aligned} & \text { En moitedume, } \\ & \text { Con tódolos que erráneos coma eu andan esparexidos } \\ & \text { [polo mundo. }\end{aligned}$
("Dende o Highland Princess", vv. 41-44)

Esperanza á que se lle canta, xa realizada, no poema que pecha o poemario. Esperanza que se cumpre nun emigrante que, ancián, regresa á súa anhelada terra, reencontrándose coa súa xuventude perdida, e calmando, ao fin, a saudade da terra e da xuventude da que fora vítima durante tanto tempo no exilio:

Ó redor da fonte nos moitos anos o soño tecera tódalas saudades do vello emigrante. Lembrábase axionllado de neno, as meixelas mollando a fronte, enchendo a boca de iagua e arrepiando aos áxiles [cágados.

A fontenla estaba á soma da ponte, na cima das [xunqueiras,

e cara a ela iba agora o vello emigrante, a curar as [doenzas

ca iauga lembrada, tecida en soños, da fonte da [mocedade.

("Volta do vello emigrante. Tapiz", vv. 36-42)

Un motivo relacionado coa saudade da terra e que é tamén común na literatura galega aparece aquí tamén reflectido neste poema de Seoane: o desexo de non morrer sen volver ver a terra materna, sen poder despedirse dela, nunha variante do motivo literario do desexo de morrer no chan materno, de fundirse na terra natal no último soño da morte:
Voltando, a facer veu realidade o garimoso soño de non morrer lonxe sen ollar novamente os montes, o mar, os boscos da Terra. O lene soño feito polos anos misericordia labrada
("Volta do vello emigrante. Tapiz", vv. 1-4)

É curioso, xa que fronte ao desexo do emigrante expresado por outros poetas (como a mesma Rosalía de Castro ou Lorenzo Varela) de repousar na terra materna, en Seoane atopamos, polo contrario, a resignación do emigrante que é consciente de que vai morrer lonxe da terra que o viu nacer, polo que se contenta con sinxelamente poder volvela ver antes de morrer. Resignación, que, non obstante, non está exenta de denuncia:

Camiño dunha vida distinta, dunha morte desvariada viñamos eiquí, vindo a vivir, vivindo de moitos [xeitos

e tamén en certa maneira, vindo a morrer nesta [chauzada

de moitas mortes iñoradas, ficando no camiño sen [cadaleitos

mortos de súpeto sobor desta terra, sen cruz, sen [viático,

sen familiares e sen veciños que fagan o pranto para [xacer

con terra e ceo por sártego, baixo iste ceo enimático, rodeiados por caranchos buxéus que se veñen [bastecer

da nosa carne apodrecida, aquecida, enxoitada polos [ventos

até que os ósos fican amárelos, brancos, roídos como [as caaveiras

dos cabalos e das vacas, envoltos en lama seca, [arañentos, mesmo loirecidas polos anos, esquecidas de Deus, [alcóntranse as oseiras.

("Ramón Cernadas", "I. Eu, Ramón Cernadas, povoador galego. 1780”, vv. 21-32)

Así, inda que a saudade está presente no desenvolvemento poético da obra de Seoane, esta apenas se presenta como unha forza pasiva ou contemplativa, senón que prevalece o ton crítico e de denuncia. Seoane quere que a súa obra non sexa só fermosa esteticamente, senón que ademais ensine, interveña activamente na historia e na concepción creada socialmente en relación a esta (Alonso Montero 2002: 87). En Seoane a saudade xa non é o lamento dorido do emigrante morriñento, senón unha forza construtiva, que lle recorda ao emigrante a súa orixe e todo o que inda lle queda por loitar. É unha saudade destapada de todo o contido 
filosófico ou ontolóxico que Piñeiro quixo darlle, moito máis humana e cotiá. É a saudade do traballador, do labrego, non a do intelectual. É a saudade vivida e non a contemplada ou teorizada. Xa non é un lamento, senón un grito esperanzado, un berro de denuncia:

Puede que todo ello [Fardel de eisilado] sea un fracaso, me siento incapaz de juzgarme, pero lo que quiero expresar en definitiva es que no se puede continuar hablando de saudade y de impulso misterioso hacia occidente cada vez que un jornalero o casero emigra para resolver su problema personal o también económico (...) Todo el sentimiento de saudade es mínimo, es más fuerte en ellos el sentido de la realidad... (Carta de Luís Seoane a Carlos Maside datada a 27/12/1952; Alonso Montero 2002: 71)

\section{José Ángel Valente, ou a pertenza ao non- -lugar}

Eu nacín en ningures. Ou non nacín. Ou nacín - de ter nacido, se ben cadra-nun lugar que xa non eisiste.

(José Ángel Valente, "III. Paxaro de prata morta”, Cántigas de alén)

Se en Luís Seoane, como analizabamos, prevalece a visión sociopolítica e económica da emigración sobre outros acercamentos, tomamos agora outro poeta, tamén "emigrante", que se aproxima ao mesmo tema dende unha perspectiva totalmente oposta á de Seoane: a intimista. Se ao falar de Seoane e da súa poesía tiñamos necesariamente que referirnos aos efectos sociais e históricos do fenómeno migratorio, con José Ángel Valente (Ourense, 1929 -Xenebra, 2000) coñeceremos os efectos íntimos, persoais e psicolóxicos que a decisión migratoria carrexa: a do exilio interior.

Neste apartado analizaremos a única obra escrita en galego polo mencionado autor, Cántigas do Alén, para explorar como nela é plasmada a relación ambigua, doente, do autor coa súa terra natal e como dela nace unha visión da saudade afastada dos discursos predominantes ao respecto, tanto sociais como poéticos.

Inda que as Cántigas foron publicadas en 1989 , son en realidade o froito dun proceso que abarca dende 1980 ata 1988 , e cuxa orixe debemos buscar na conferencia sobre as cantigas de Alfonso X ofrecida polo escritor en Xenebra en 1980 e que supuxo para o ourensán o "reencontro" coa súa lingua natal, o galego. Os poemas recollidos en Cántigas do Alén constitúen o poemario Sete cántigas de alén publicado en 1981 máis oito poemas primeiramente publicados na prensa entre 1985 e 1988 (Martínez-Falero 2010: 80).

\subsection{A emigración como decisión persoal}

José Ángel Valente coincide con Luís Seoane na súa condición de emigrante e de intelectual bilingüe (nesta última tamén coincidirá Manuel Rivas). Son estes dous importantes aspectos a ter en conta á hora de analizar a poética e a noción de saudade nos nosos autores, xa que como nos indica Margarita García Candeira, este tipo de escritores, "polo seu emprazamento en dúas (ou máis) literaturas, desafían nocións monolíticas da identidade colectiva baseadas na correspondencia monolóxica entre lingua e nación" (2013: 110), o que será fundamental á hora de concibir un concepto de saudade menos restritivo ao proposto por correntes nacionalistas como o piñeirismo.

A diferenza de Seoane, a marcha de Galicia de José Ángel Valente foi, principalmente, froito dunha decisión persoal. Ao longo da súa vida, o ourensán viviu en diferentes cidades e países europeos, e inda que as causas da súa peregrinaxe, principalmente políticas ou laborais, difiren dunha cidade e dun país ao outro (Martínez-Falero 2010: 81), a fuxida da pechada sociedade franquista foi unha causa capital. Héctor Mera Herbello relaciona este desarraigo primeiro coa patria chica (tanto literario como vital) coa experiencia traumática da guerra civil $^{8}$ (2002: 143). Fose como fose, e inda que seguramente habería que sumar máis elementos á nosa ecuación para acadar un cadro completo da marcha de Valente de Galicia (os motivos que rexen as decisións da nosa vida adoitan ser normalmente máis complexos e numerosos), si é importante ter presente que a marcha do escritor foi unha decisión consciente, tomada polo propio autor. Estes datos biográficos van ser importantes á hora de analizar as Cántigas xa

8 Así, nas súas Cántigas de alén, Valente escribe: "Eu nacín en ningures. Ou non nacín. Ou nacín -de ter nacido, se ben cadra- nun lugar que xa non eisiste. Por iso lle chamo Ausgasquentes. Non lle atopo outro nome na miña memoria, por máis que nela furgo. (...) Porque tamén a casa onde coido aqueceu ese presunto nacemento ten sido demoída e xa nada fica dela, nin cimentos nin ren. (...) Tamén dende aquel balcón deberíase ouvir posiblemente o pranto polo Andrés Nieto, que morreu ou foi morto deseguida ós comezos da guerra, non sei onde. ¿Tiña sido en Asturias? Pranto e medo de tódolos xeitos naquel tempo, cando a terra estaba sementada de morte" (2017: 59). 
que o poemario presenta o conflito identitario entre o eu poético que decidiu marchar e aquel que se pregunta polo eu que puidera ser se decidise quedar en Galicia. Poeticamente prodúcese o encontro con ese outro posible 'eu', un 'eu' que non foi, pero cuxo ser en potencia encárase con el e aparéceselle en forma de ausencia. O 'eu' que puido ser non foi vencido polo 'eu' que tomou a decisión de marchar, e, polo tanto, o regreso á terra natal preséntase como un reencontro do 'eu' presente con ese outro 'eu' que permanecera escondido entre as tebras galegas (García Candeira 2013: 111).

Ese outro 'eu' que xa nunca poderá ser preséntase no poemario en forma dunha sombra ante un espello, un enigma que necesita ser descuberto, unha identidade baleira á que é preciso preguntar, sen que por iso se constitúa como un arrepentimento, ou polo menos, non explícito (Ibid.: 113). Como ben nos indica García Candeira, este "lamento retroactivo polo que non foi" é característico da literatura asociada ao exilio, especialmente latente entre os exiliados intelectuais, xa que estes adoitan cargar con certo sentimento de culpa (Ibid.: 112-113).

O reencontro coa Galicia perdida presentado nas Cántigas realízase tanto no plano físico ("Estou no adro/ onde aquel día o grande corpo/ de meu abó ficou"9) como no lingüístico. Todos os críticos están de acordo en sinalar a importancia que a linguaxe ten no único poemario escrito en galego do autor, xa que Valente sente o seu exilio neste dobre plano físico/ lingüístico, de modo que a colección de poemas constitúe un lamento por esas "palabras que, relegadas e esquecidas, acumulan a dor e tórnanse ferintes" (Ibid.: 114). O simple retorno físico a Galicia que describe o poemario non é só tal experiencia; é ante todo unha viaxe sentimental, xa que Valente regresa ao lugar da nenez e, polo tanto, ao idioma que aprendeu de neno e ao fogar, lugar predilecto da memoria e dos retornos (Martínez-Falero 2010: 80). É tamén unha viaxe ao seu interior e ás posibilidades de si mesmo perdidas.

\subsection{A saudade das cántigas}

\section{A Saudade é unha sede insanciable de algo que, ás veces, non se sabe o que é. \\ (Castelao, Sempre en Galiza)}

É por todo o anteriormente exposto que a volta á terra proposta por Valente preséntase en realidade como un acto malogrado, polo que todo o poemario acaba constituíndo "unha tentativa sempre falida de retorno a un fogar problematizado" (García Candeira 2013: 111). Seguindo esta lóxica, a visión que Valente presentará da saudade non poderá ser nunca unha visión romantizada dela, toda vez que non o é o espazo ao que a referida saudade alude e se dirixe. Aquí a saudade preséntase baixo a forma de señardade (Ibid.: 119), é dicir, baixo a máscara da soidade. Non podemos esquecer que 'saudade' e 'soidade' son dúas palabras intimamente relacionadas entre si, tomadas en máis dunha ocasión como sinónimos ${ }^{10}$. Como analizabamos ao estudar o pensamento de $\mathrm{Pi}$ ñeiro, na saudade-soidade adoitan agocharse as concepcións máis metafísicas da saudade. E así vai ocorrer tamén no caso das Cántigas, onde a saudade será a encargada de cumprir o papel de intermediaria entre os dous irreconciliables 'eus' poéticos anteriormente presentados; será o conduto que fará posible a rotura da fronteira física, dando lugar así a unha idea más ampla, máis aberta, de espazo e de pertenza, ofrecéndonos unha "proposta sobre a identidade galega baseada na desterritorialización" (Ibid.: 109).

Respecto a este papel que a saudade desenvolve no poemario de conxugadora de opostos, tamén temos que lembrar que esta é unha configuración historicamente moi produtiva na literatura. O mesmo Castelao definía nas páxinas de Sempre en Galiza a saudade ${ }^{11}$ do seguinte modo: "Quén sabe se a saudade galega non será outra cousa máis que a loita de dous anceios incompatibles: o de estar e non estar na Terra!" (1977: 229). Parece que Valente se fai cargo desta acepción da saudade, e tal

\footnotetext{
Cántiga III.

10 Carolina Michaëlis de Vasconcelos sostén que a raíz de ambas palabras é a mesma, o latín sOLiTATES (2016: 50-51), e en poetas do Rexurdimento como Francisco Añón ou na mesma Rosalía de Castro o termo soidade é usado coas mesmas connotacións que o vocablo saudade.

11 Curiosamente, e en relación ao "alén" que dá título o poemario de Valente, tamén deixou escrito o de Rianxo: "A Saudade tem Além i endexamáis pode conducirnos â desesperanza, porque coa ilusión do "máis alá" fuximos do mundo real e chegamos aos mundo ensoñados; podemos crear países de fadas, paradisos de felicidade, até confundir a nosa Terra co Ceo" (Castelao 1977: 355).
} 
saudade debuxa no seu poemario, intentando atopar a través dela e da súa poesía o medio para romper a dicotomía entre o estar e o non-estar, entre o ficar e o marchar:

Voltei. Nunca partira.

Alongarme somente foi o xeito

de ficar para sempre.

(Cántiga III, vv. 6-8)

Con versos como estes Valente parece querer dicirnos que é posible estar no lonxe, que é posible pertencer á distancia. A distancia, e o seu mesmo concepto, pode ser tamén un lugar, un lugar de pertenza (García Candeira 2013: 117), polo que, ademais de todo o exposto anteriormente, Valente preséntamos tamén aquí unha proposta identitaria e territorial non baseada na pertenza ou, mellor dito, na presenza física, senón na ausencia.

Ao respecto, queremos destacar outra pasaxe, o verso 7 da quinta cántiga que di: "Terra allea e máis nosa, alén, no lonxe". Aquí, unha palabra destaca sobre todas as demais e condensa, xa dende o mesmo título, a importancia da rotura do espazo e a proposta de ampliación dos límites físicos e xeográficos do ourensán: o alén. $\mathrm{O}$ alén, igual que a saudade, preséntase no poemario como un dos elementos vertebradores da rotura do espazo e da dicotomía ir(se)/quedar(se), estar/non estar (García Candeira 2013: 117).

Ademais, fronte á idea romántica e simplista da saudade, o sentimento en Valente convértese en "nostalxia violenta" (Ibid.: 111). A distancia, o afastamento, a saudade convértense na poesía do ourensán en algo problemático ${ }^{12}$. En Valente, o afastamento do fogar primeiro non implica unha sublimación da terra perdida, como ocorre en boa parte da literatura ao respecto, senón que nas Cántigas esta preséntase como un elemento distanciador que permite unha óptica maior e máis certeira dos obxectos, unha visión máis clara e nítida deles que impide tal idealización (Ibid.: 115). O mesmo Valente definiu a saudade recollendo este carácter conciliador, complexo, problemático e contraditorio:

Tener saudade es tener soledad, tener soledad de algo a lo que se quisiera a la vez volver y no volver, porque la saudade aleja y acerca, separa y aproxima, es decir, nos pone ante las cosas a la distancia necesaria para verlas mejor y nos une a ellas con una nueva y acaso ya no perecedera vinculación. (Valente 2008: 1147)

Ben é certo que, ontoloxicamente, a saudade se alimenta dos opostos, ou polo menos así foi numerosamente definida. En Teixeira de Pascoaes, por exemplo, un dos principais teóricos portugueses do termo, é común a definición do sentimento en base á contraposición de opostos que conseguen unirse na experiencia saudadosa: o amor e a dor, o bico e a bágoa, Venus e María (é dicir, paganismo e cristianismo), ceo e terra, corpo/materia e espírito... (1988: $25,48)$. Valente non foi, polo tanto, o primeiro en atopar na saudade un reconciliador de opostos, un elemento que tanto "separa como aproxima". Torres Queiruga diría dela que posuía a capacidade de facer da ausencia, presenza, xa que ao evocar o que nos falta (fisicamente), facémolo presente (espiritual ou mentalmente) (1980: 18). Tamén, segundo Ramón Piñeiro, a través da saudade prodúcese a temporalidade do intemporal e a intemporalidade temporalízase (Piñeiro 2001: 80). Os exemplos poderían ser en realidade moitos. Como de novo nos indica García Candeira, a proposta desterritorializadora de Valente non é nova dentro da tradición literaria e cultural galega: "Fronte ao impulso reterritorializador dos rexionalismos, as cántigas valentianas pertencen a unha tradición desterritorializada de particular relevancia na literatura e cultura galegas" (2013: 120). A través desta proposta, Valente non só se posiciona a favor desta corrente desterritorializadora, senón que entronca tamén con outros autores como o anteriormente presentado Luís Seoane, xa que os dous se opoñen, a pesar das diferenzas formais e temáticas, á visión saudosista e nacionalista de Piñeiro (Ibid.: 120). Ademais, debido á relación complexa e ambigua de Valente coa lingua galega (García Candeira fala del como dun "estranxeiro na propia lingua"), as Cántigas supoñen tamén un "xeito de resistencia contra o control da lingua que exercen os mecanismos institucionais e, neste senso, supón outro cuestionamento da asociación entre lingua e nación ou estado" (Ibid.: 118), ideas tamén presentes en Seoane ao reclamar

12 Curiosamente, no entanto, para outros estudosos como Héctor Mera Herbello, na poesía galega de Valente, na visión da Galicia reencontrada, prevalecen os aspectos positivos sobre os negativos (2002: 144-145). Tamén Luis Martínez-Falero coincide nesta interpretación, ao ver plasmada Galicia como lugar de "idealizada naturaleza", como "territorio mágico y mítico" (2010: 82). 
a importancia dos elementos transatlánticos na cultura galega.

\section{Manuel Rivas e a súa Galicia 2.0: a iden- tidade na era da globalización}

A exposición da saudade que realizaremos a continuación, inda que toma o conxunto da obra do escritor Manuel Rivas (A Coruña, 1957-), céntrase especialmente na análise do seu artigo periodístico "Galicia contada a un extraterrestre", publicado por primeira vez no periódico El País con data de 14 de outubro de 2001, así como, revisado, no libro Unha espía no Reino de Galicia, publicado en 2004 en galego e en 2006 en castelán, e que pode ser considerado como unha "carta de presentación" da idea de Rivas de Galicia, da Galicia que plasma nas súas novelas e relatos.

Á hora de analizar esta Galicia que Rivas nos presenta, temos que sumar á nosa análise elementos recentes da nosa sociedade actual como a globalización ou a democratización do acceso a internet e como estes influíron na modificación de conceptos como "saudade", "distancia" ou "identidade", tanto nacional como persoal. Sen estas reflexións previas unha análise destes conceptos na obra do coruñés non sería certeira, como intentaremos expor deseguido.

Na nosa sociedade moderna, internet (e incluso outras formas recentes de comunicación como pode ser a publicidade ${ }^{13}$ ) preséntase como un novo medio que axuda a crear a idea de "nós", especialmente entre unha comunidade cun forte espallamento territorial, como é o caso de Galicia. Internet funciona como unha forza dinámica de dobre dirección: ao mesmo tempo que nos abre ao exterior e nos fai partícipes do mundo globalizado, rompendo fronteiras e os tradicionais conceptos de tempo e espazo, posúe tamén unha forza centrífuga cara ao local. Esta constitúe sen dúbida un dos máis significativos cambios que trae consigo a revolución dixital: a alteración da nosa percepción do tempo e do espazo (Peris 2010: 225), e vén da man de procesos como o recentemente acuñado de "glocalización":

Algunos de los estudios que han profundizado con más rigor sobre la globalización revelan cómo al mismo tiempo que ésta favorece procesos de desterritorialización, gracias a la transformación de las coordenadas espacio-temporales, se producen una serie de prácticas culturales en sentido inverso. Es lo que se conoce como glocalización [...] Esas fuerzas globales, por tanto, se enfrentan con una amplia variedad de resistencias de tipo cultural con las que establecen un diálogo que no siempre acaba con una mera imitación. [...] Cada sociedad retranscribe los signos transnacionales, los adapta, los reconstruye, los reinterpreta, los 'reterritorializa'. (Ibid.: 245)

Ben é certo que historicamente estas prácticas de "reterritorialización" non constitúen unha práctica nova pero, como ben indica Peris, "lo que diferencia el momento actual de épocas anteriores es que estas maneras de organizarse culturalmente se pueden llevar a cabo sin la necesidad de vincular tiempo y espacio" (Ibid.: 245). É dicir, internet facilitou e incrementou a forza destes movementos e hibridacións. É por todo iso que podemos afirmar que a democratización do acceso a internet produciu a aparición de novas formas de nacionalismo e de xeitos de entender os tradicionais conceptos de "pertenza", "orixe" ou "fogar". Así, Benedict Anderson fala da existencia de "nacionalismos de longa distancia" e Edenson acuñou o termo "nacionalismo de cada día" para intentar recoller e analizar estas novas formas de pertenza a grupos, comunidades ou lugares dos que podemos estar fisicamente lonxe. É concretamente a isto ao que fai referencia o termo "nacionalismo de cada día": ao feito de poder estar en continuo e permanente contacto virtual co noso lugar de orixe con independencia da distancia en quilómetros ou en horas de transporte que nos separen del. Esta facilidade dixital e virtual para sentirnos alí onde realmente non estamos e o que, seguindo a Edenson, permite este desenvolvemento dunha identidade nacional a pesar da desterritorialización das fronteiras (apud Peris 2010: 245). Intimamente conectado con este, o chamado "nacionalismo de longa distancia", pola súa banda, fai referencia especialmente as comunidades na diáspora e como estas usan, en particular cando non teñen unha base territorial que as sosteña, como é o caso da comunidade kurda, as facilidades de internet e das novas tecnoloxías para consolidar, reforzar e definir a identidade colectiva (Ibid.: 245).

Dentro do campo dos estudos galegos, temos que destacar a José Colmeiro como un dos

13 Ao respecto, é de interese o traballo de Rodríguez Fontela (2014), no que a autora analiza algún dos máis recentes anuncios publicitarios das empresas Gadis e Campofrío e a visión nacional galega/española que neles é presentada. 
principais investigadores ao respecto. Colmeiro segue a estudosos como García Canclini na procura dun actualizado método de análise cultural que teña en conta a complexa hibridación producida nas periferias como a galega, poñendo a énfase en conceptos de recente acuñación como "glocal", é dicir, a interacción e interdependencia do local co global (2013: 132). No seu artigo "Visións periféricas, posicións globais: resituando a cultura galega contemporánea", Colmeiro propón "a desterritorialización do mapa cultural galego para superar vellas exclusións baseadas no xénero, a orixe nacional, a lingua ou a demarcación territorial e o desmantelamento da dicotomía centro/periferia que relegou a cultura galega ás marxes [...] abrir Galicia e os estudos galegos ao diálogo co exterior na era global" (2013: 132). Colmeiro é un firme defensor dunha "Galicia sen fronteiras"14.

Manuel Rivas encádrase tamén dentro desta corrente de pensamento de apertura das fronteiras, físicas e mentais, e da procura dos espazos identitarios de hibridación ${ }^{15}$, polo que a súa obra constitúe un reflexo da nova sociedade dixitalizada e interconectada do século XXI e do choque entre sociedade tradicional e moderna tan presente na actual Galicia.

\subsection{Galicia emigrante}

\section{Galicia foi pobo escollido polo Adeus \\ (Manuel Rivas, \\ Unha espía no Reino de Galicia)}

A cosmovisión galega de Manuel Rivas fai fincapé en importantes aspectos da socioloxía, historia e cultura galegas que teñen unha relación directa coa idea de saudade. Un dos máis destacados, é, sen lugar a dúbidas, a historia migratoria, un dos elementos que Rivas considera definitorios da sociedade galega:

A maior cidade de Galicia segue a ser Bos Aires.

O maior cemiterio galego, o de Cristóbal Colón, na Habana. Máis de dous millóns de galegos emigraron durante o século XX. O éxodo comezara en forma masiva coas fames negras de meados do século anterior, provocadas pola peste da pataca, como na Irlanda. (Rivas 2004: 20)

De feito, a obra literaria de Rivas está repleta de personaxes vinculadas a emigración (Castro-Vázquez 2004: 88). Para Manuel Rivas, ademais, este histórico fluxo migratorio implica a creación dunha identidade "diferente fruto de la combinación de culturas" (Ibid.: 85) e o ensanchamento da xeografía cultural (Pardellas Velay 2016: 10), a perda de importancia das fronteiras puramente xeográficas: "Mais Galicia está e non está en Galicia. É un lugar e tamén un des-lugar ou un Non lugar" (Rivas 2004: 11). A distancia, igual que viamos que ocorría na poesía de José Ángel Valente, convértese nun algo modelable. Como dirían Heredeiros da Crus: "De Jalisia ao estranxeiro hai catro metros e medio":

Cando se explica, parece que o galego ten que loitar contra a idea de Galicia como terra remota. A distancia, ti sábelo moi ben, é algo subxectivo. Oír un labrego describir así o destino de dous de seus fillos, emigrantes: «Un anda pertiño de aquí, por Bos Aires: o outro, lonxe, nun sitio moi raro, Frankfort ou algo así.» El sabía o que quería dicir. Hai periferia e centro no universo? É unha idea que ten que ver co poder ${ }^{16}$. (Rivas 2004: 16; o itálico é noso)

Manuel Rivas non cre nas fronteiras ${ }^{17}$, e moito menos cre nelas como elementos definitorios dunha identidade cultural (Bazán Rodríguez 2008: 157). Normalmente en Rivas as fronteiras, se aparecen, non son con boas connotacións, como ocorre no poema "Fronteira", incluído primeiramente no seu poemario Ningún cisne:

Un dos mozos portugueses levaba baixo o brazo os zapatos novos.

14 De feito,Galeg@s sen fronteiras é o título dunha das súas máis recentes publicacións, unha serie de entrevistas con personaxes relevantes da cultura galega, entre eles, o propio Manuel Rivas, publicada por Xerais en formato ebook en 2013, e que leva por subtítulo Conversas sobre a cultura galega no século XXI.

15 "Mi idea de cultura es lo local-universal. Te tiene que preocupar lo que está sucediendo allá donde estés, escuchar a la tierra, a la gente, pero solo tiene sentido esa cultura si no tiene paredes. Esa es la manera de que se convierta en algo universal. Yo en Buenos Aires antes me sentía anfibio, pero ahora ya me siento pez, estoy en mi agua. A veces me siento más náufrago en Galicia que aquí" (Rivas 2016).

16 A referencia á periferia, ao centro e ao poder conecta tamén coas ideas de José Colmeiro expostas anteriormente.

17 Noutro punto do referido texto di: “A min xa me gustaría ter tamén pasaporte portugués. [...] Si, amigo, ter catro ou cinco pasaportes, catro ou cinco identidades no peto" (2004: 11-12). De forma parecida, nunha recente entrevista a El País afirmaba: "Creo que es fenomenal: frente a las identidades excluyentes y que negaban al otro, descubrir que puedes tener varias identidades y que estás mucho más a gusto, tu cuerpo se vuelve mucho más erótico, es una relación más gozosa con tu propia identidad" (Rivas 2016). 
Foi ese o que morreu co tiro.

O garda puxo o xeonllo en terra e disparou.

Cando a nai cruzou a fronteira,

só os nenos estabamos alí.

Estendeu o mandil e arrepañou a terra ensaguentada. Non quero que fique nada aquí.

(Rivas 2003: 217)

Manuel Rivas, entroncando coas teses tamén defendidas por José Colmeiro, é un firme defensor de Galicia como "aldea global" (Vaz 2012). Para Rivas, a sociedade galega é ante todo unha sociedade filla da emigración ${ }^{18}$, o que a converte nun "pueblo que tiene como punto alto de su cultura integrar y escuchar todo lo que viene desde fuera por la vía de la emigración" (Nascimento 2011: 5). O mesmo Manuel Rivas expón mellor que ninguén outro cal é a súa idea de Galicia, da súa Galicia ideal, a que promulga tanto a través da súa escritura literaria como a través do seu quefacer xornalístico. A Galicia que soña e na que cre:

Xa en 1916, as Irmandades da Fala definiron así o país: «Galicia, célula de universalidade.» $\mathrm{E}$ fecunda esta idea. Galicia como célula nai. Como matriz. Como almeiro. [...] Se re-pensamos o atlas, atoparemos Galicia como un posíbel lugar de encontro continental e transantlántico, un magnífico «meeting point», un grande espazo portuario da fusión cultural, con peiraos para todas as achegas e partidas, onde os guindastres da imaxinación embarquen e desembarquen tradicións reinventadas, novas heterodoxias, errantes periferias, expresións fronteirizas de espíritu «pel roxa». Un mar de mares. Un porto soñador da Europa fisterraica onde converxer e ecoar vagas culturais hispanas, portuguesas, africanas, americanas... ou mesmo do teu planeta, amigo Golf. [...] En Galicia hai un pouso forte de identidade, pero non excluinte. É un bo lugar para compartir, para sumar identidades. [...] Só nese imaxinar leveda outra realidade. [...] Unha Galicia de memoria activa e non de souvenir, de memoria andante, aventureira, que exerza o humano dereito fundamental a imaxinar. Por que non? (Rivas 2004: 35-36; o itálico é noso)

\subsection{A saudade en Manuel Rivas}

Todas estas ideas expostas en torno á emigración e o territorio implican, indubidablemente, a creación dun discurso en torno á saudade que vai diferir do discurso tradicional e simplista de asociación da saudade a un territorio e a unha forma de sentir dorida e paciente.
Falabamos anteriormente de como o espazo físico se configura na obra de Rivas en base á condición emigrante da sociedade galega. E tamén analizabamos, ao definir a saudade e a variante da saudade morriñenta como esta está directamente vinculada a idea de lugar. É dicir, para poder botar en falta un espazo físico, unha terra, esta ten que existir como tal. Agora ben, Rivas, na súa obra literaria e periodística preséntanos un lugar, Galicia, que, segundo as súas propias palabras, está e non está ao mesmo tempo dentro das súas fronteiras. A saudade presentada por Rivas vai un paso máis alá da saudade tradicional: a morriña agora pode ser tanto dun espazo físico como dun espazo mental, inda que non é novidoso o feito de que Rivas asocie a saudade á perda dun ideal, dunha idea, é dicir, a un ente non físico. Esta forma de saudade é especialmente prototípica da saudade da patria ou da saudade na súa vertente ontolóxica. Pero si presenta Rivas un interesante matiz na súa saudade que non é usual encontrar plasmado noutros autores, especialmente os anteriores: o abandono do espazo físico non e condición sine qua non para a aparición do sentimento morriñento:

Siempre se habla de saudade o de morriña pensando en la del inmigrante, del que se marcha del país de origen, pero casi tan intensa, a veces más, es la saudade del que se queda, del que no marcha. Es un doble camino. Conocí a un señor en la Costa da Morte que todos los días subía con sus vacas a mirar el mar, a un lugar inhóspito. Sus seis hermanos se fueron a Argentina. Y él no, se quedó con las tierras. Lo contaba como un enorme desgarro. "Nunca fui capaz de ir", decía con culpa. Ya tenía 80 años y sabía que nunca iría. (Rivas 2016)

Isto débese ao feito anteriormente exposto de que o espazo (Galicia) en Rivas no é tan só un lugar físico, senón que é, ante todo, un espazo mental, unha idea, unha forma de ver o mundo:

A máis fermosa definición do galego deuna un vello emigrante entrevistado na televisión. «Está vostede orgulloso de ser galego?» $\mathrm{O}$ home mirou ao público, mirou logo a cámara e dixo: «Estou moi orgulloso de ser galego porque galego, galego, pode selo calquera.» Ou estoutra frase, dun mariñeiro que agora traballa de operario no camiño de ferro en Nova Celandia: «Vin tanto mundo que son máis galego que ninguén.» (Rivas 2004: 18)

18 "Galicia é aldea global desde hai tempo. Pola intensa emigración [...] E polo traballo nos mares" (Rivas 2004: 19). 
Esta é, por outra banda, unha visión, unha concepción de Galicia, de fundamental percorrido entre os autores galegos. Nacional e poeticamente, a idea de Galicia sempre estivo máis asociada a unha fala e a unha cultura que a un territorio, como resumo, por poñer tan só un coñecido exemplo, os versos de Manuel María incluídos no seu poemario infantil Os soños na gaiola (2008):

Galicia é o que vemos:
a terra, o mar, o vento...
Pero hai outra Galicia
que vai no sentimento!

Galicia somos nós: a xente e mais a fala.

Se buscas a Galicia

en ti tes que atopala!

O segundo aspecto que nos interesa destacar da visión saudosista de Rivas é a crítica que realiza á tipificación do sentimento saudoso como identitario da sociedade galega, así como a utilización política (ou social) que del se realiza en ocasións:

Galicia é morriña. Teño morriña, teño saudade. É unha palabra que exportamos. Que xa aparece noutros dicionarios. No da Real Academia Española. No Collins inglés. É unha verba que che envío como agasallo, para que a difundas no teu planeta, mais adminístraa con prudencia. Morriña significa botar de menos algo, ter nostalxia, sentir melancolía. Está asociada a unha historia de dor, de perda, de emigración. Eu escoitei nalgún centro de emigrantes, na noite invernal de Suíza, algunha balada de morriña que parou nas doce da noite os reloxos de cuco e puña os pelos crechos. Como a saudade no fado portugués ou a morna caboverdiana. [...] Mais ten tino coa morriña. Hai que tomala na dose xusta. Colgou ao galego cun sambenito de pobo. E ademais é un comodín que o mesmo serve para un discurso electoral que para unha dor de moas. (Rivas 2004: 24; o itálico é noso)

Ao respecto, é especialmente interesante a referencia ao discurso electoral. Debemos ter en conta que o artigo ao cal nos referimos ao longo desde ensaio foi publicado nos momentos previos ás eleccións autonómicas galegas de $2001^{19}$. O que critica Rivas no devandito parágrafo do artigo é o uso político que do termo se ten feito desde a dereita política (especialmente, inda que non só) para captar o voto da poboación emigrante a través da apelación ao sentimento de morriña, facendo da saudade un trazo característico da identidade galega, pero un trazo pasivo, despoxado de calquera tipo de forza contestataria ou subversiva ${ }^{20}$, como a demandada por Seoane na súa obra. Así, a saudade emprégase para aludir á nostalxia do emigrado co único fin da súa utilización política nas urnas (Martínez Quiroga 2014: 216-217). A crítica de Rivas cara a este feito amósase tamén noutros dos seus artigos, como o titulado "A esquerda desanimada", primeiramente publicado nas páxinas do xornal A Nosa Terra e posteriormente recollido no volume Unha espía no reino de Galicia:

O outro día apareceu unha gralla moi chusca nun anuncio de prensa. Chamaban Centro de Saudade da Xunta a un Centro de Saúde. Pois iso é o que vén facendo dende hai anos a dereita saudosa en Galicia: Poucos centros de saúde e moitos centros de saudade. Unha auténtica rede de desánimo instalada por Galicia enteira. O maior éxito deste goberno é a marca acadada no PID (Produto Interior de Desánimo). Por iso amólalles tanto o Nunca Máis. Porque é bo para todo, como o allo. Para a reuma. Para o raquitismo. Para a insuficiencia respiratoria. Para os meigallos. Para a saúde e para a saudade. (Rivas 2004: 152)

19 De feito, a primeira das versións do texto, a do artigo publicado en El País, comeza así: "Un total de 30.000 kilómetros cuadrados y 1.200 kilómetros de costa. Una población de 2,8 millones de personas, 1 millón de vacas y 500 millones de árboles. Así es Galicia. Clásica y moderna. Hasta un extraterrestre reconocería esta tierra, que el próximo domingo celebra elecciones" (Rivas 2001).

20 No citado artigo de Pilar Martínez-Quiroga, a autora realiza unha detallada análise de como outros elementos, como o folclore, foron tamén tomados polos sectores conservadores da sociedade para así desactivalos dos elementos ideoloxicamente contrarios ao promulgado polos partidos políticos de dereita: "Como diciamos o PP galego apropiouse dos signos diacríticos da identidade cultural galega, o cal prexudicou o nacionalismo galego. Así os galegofalantes vían na televisión que o galego, de coñecemento obrigatorio na administración, só era empregado polos representantes políticos cando falaban sobre gastronomía, música, folclore ou calquera acto rural, afastado de calquera signo de progreso económico ou da "alta cultura" [...] Esta forma da dereita de considerar a cuestión identitaria galega é semellante a defendida pola Ditadura franquista. Ao apropiarse dos símbolos tradicionalmente galegos, a dereita usurpou o ámbito de acción e de discurso que lle correspondería ao nacionalismo, o cal se viu na obriga de atopar outra vía para a reconstrución dunha identidade galega. A alternativa que lle queda ó nacionalismo galego é recuperar o voto urbano e da xuventude como está a facer na actualidade” (Martínez-Quiroga 2014: 220-221). 
Malia iso, Manuel Rivas non nega o peso identitario que a saudade e o discurso construído ao seu redor poida ter na sociedade galega, pero oponse á visión simplista, excluínte e pasiva do seu uso: "A fórmula dun presunto carácter galego sería $\mathrm{H}+\mathrm{M}=\mathrm{I}$ (Humor máis Morriña, ou melancolía, igual a Ironía). Melancólicos somos todos, pero o que de verdade ten prestixio en Galicia é o humor" (Rivas 2004: 26). Detrás dese humor, desa retranca tan presente na súa obra, pódese apreciar, ao ler detidamente, a saudade dunha terra soñada e dun futuro mellor para ela, dunha esperanza nela, como a esperanza de regreso do emigrante: "Diante dun prato de patacas, aínda que estea cheo de exquisiteces, o galego sente unha especie de baleiro metafísico. O galego ten efectivamente saudade, pero a expresión máis radical da saudade é a saudade das patacas" (Ibid.: 98). Pódese resumir máis certeiramente?

\section{Conclusións}

Trala nosa análise, e malia as diverxencias de estilo, temática e incluso xénero que presentan os tres autores analizados, si podemos apreciar entre eles algúns puntos de coincidencia, e incluso un certo proceso evolutivo ao respecto dalgúns aspectos que consideramos de interese destacar.

En primeiro lugar, cronoloxicamente podemos apreciar unha progresiva desvinculación entre os conceptos de saudade e espazo físico, especialmente patente na poesía de José Ángel Valente e na visión literaria e vital de Manuel Rivas. Fronte ao tratamento dado á saudade polos poetas do século XIX, segundo nos imos acercando ao novo milenio, o lugar que proxecta agora o sentimento saudoso vaise volvendo máis etéreo, un espazo máis mental que real. Ou para dicilo doutra maneira, as fronteiras do espazo real e físico esfúmanse, podendo alongarse ou desprazarse á vontade.
En todas estas novas concepcións de saudade presentadas, a desterritorialización preséntase como un factor clave para entender unha nova construción da identidade galega e o glocal como un factor en alza. Ideas que non só demandan unha nova visión da saudade e da identidade galega, unha identidade híbrida e aberta ao mundo; senón tamén das relacións de poder, claramente presentadas no discurso literario de Seoane, a través da crítica económica (o emigrante emigra pola necesidade de gañar o pan e non por ningunha clase de sentimento que o predispoña a iso, é dicir, debido á situación de atraso económico que vive o país) e no discurso de Rivas a través da crítica política (o sentimento saudoso non pode converterse nunha arma política), e, de forma máis velada, nas Cántigas de alén: "A condición resistente do desprazamento vén sendo enfatizada por certas correntes de pensamento crítico, que ven como a ruptura do vínculo entre territorio e individuo, a través da permanencia e a pertenza, desafía o control do poder" (García Candeira 2013: 117).

No entanto, isto non quere dicir que esta nova visión da saudade desterrara a visión máis clasicista ou tradicional dela, senón que se produce unha convivencia entre ambas, creando un campo artístico, literario e identitario moito máis rico tanto en significados como en matices. Inda a cantante Ses, unha das voces máis comprometidas e rebeldes do panorama musical galego, canta: "E a noite longa é tan dura / que as saudades se instalan, / pero que non pense a lúa / que o sol non vén para botala" 21 , identificando a falta de luz da noite coa falta de luz no espírito, traducido en forma de sentir "saudades".

Visións da saudade que conviven nunha Galicia que vai na procura dunha visión máis aberta de si mesma, intentando escapar da visión inmobilizadora de termos tan cargados de significados e significantes como o de saudade.

\section{Referencias bibliográficas}

Alonso Montero, Xesús (1972): Rosalía de Castro. Madrid: Júcar. (2002): As palabras do exilio. A Coruña: La Voz de Galicia.

Bazán Rodríguez, Óscar (2008): “El lápiz del carpintero: la voz de los silenciados", Siglo XXI. Literatura y Cultura Españolas 6, pp. 151-160.

Cabanillas Enríquez, Ramón e Eladio Rodríguez González (2000): A saudade nos poetas gallegos. Santiago de Compostela: Xunta de Galicia.

Casas, Arturo (2010): "Individuo e grupo na obra poética de Luís Seoane", Raigame: revista de arte, cultura e tradicións populares 33, pp. 17-21.

Castelao, Daniel Rodríguez (1977): Sempre en Galiza. Madrid: Akal.

21 Estrofa da súa canción "Semente de vencer", incluída no disco Opoñerse á extinción, lanzado en 2016. 
Castro-Vázquez, Isabel (2004): El lenguaje ecológico de Manuel Rivas: retranca, resiliencia y reexistencia. Tallahassee: The Florida State University.

Colmeiro, José F. (2013): "Visións periféricas, posicións globais: resituando a cultura galega contemporánea”, Grial: revista galega de cultura 198, pp. 131-143.

Fernández Martínez, Antía (2017): "Nacionalismo, saudade, mito e historia en Fernando Pessoa y Luís Seoane", Madrygal. Revista de Estudios Gallegos 20, pp. 41-52.

García Candeira, Margarita (2013): “"Eterno inretorno»: melancolía e desterritorialización nas Cántigas de alén de José Ángel Valente", Abriu. Estudos de textualidad no Brasil, Galicia e Portugal 2, pp. 109-122.

Landeira, Ricardo L. (1970): La saudade en el renacimiento de la cultura gallega. Vigo: Galaxia.

María, Manuel (2008): Os soños na gaiola. Vigo: Xerais.

Martínez-Falero, Luis (2010): "Las Cántigas de Alén de José Ángel Valente: tradición y ruptura de la poesía gallega", Madrygal. Revista de Estudios Gallegos 13, pp. 79-87.

Martínez-Quiroga, Pilar (2014): "Unha espía no Reino de Galicia de Manuel Rivas: O humor e a construción da identidade nacional galega", Revista de Filología Románica 31/2, pp. 209-226.

Méndez Ferrín, Xosé Luís (2011): “Seoane no 'Fondo dos Espellos'. Notas para un libro de memorias que se cadra non escribo", en R. Villares (ed.), Emigrante dun país soñado: Luís Seoane entre Galicia e Arxentina. Actas do Congreso Internacional Luís Seoane "Galicia-Arxentina, unha dobre cidadania". Santiago de Compostela: Consello da Cultura Galega, pp. 339-351.

Mera Herbello, Héctor (2002): “Análise crítica das Cantigas de Alén de José Ángel Valente”, Revista de lenguas y literaturas catalana, gallega y vasca 8, pp. 139-156.

Miguélez-Carballeira, Helena (2014): Galiza, um povo sentimental? Género, política e cultura no imaginário nacional galego. Santiago de Compostela: Através Editora.

Nascimento, Magnólia Brasil Barbosa do (2011): "Un escritor poscolonial: Manuel Rivas y la escritura de la alteridad", en R. Macciuci (dir.), II Congreso Internacional de Literatura y Cultura Españolas Contemporáneas (La Plata, 3 al 5 de octubre de 2011). Diálogos Transatlánticos. La Plata: Universidad Nacional de La Plata, vol. 1, s.p., http://sedici.unlp.edu.ar/bitstream/handle/10915/31450/Documento_ completo.pdf? sequence=1\&isAllowed=y [consulta: 18/08/2018].

Pascoaes, Teixeira de (1988): A saudade e o saudosismo: dispersos e opúsculos. Lisboa: Assirio \& Alvim.

Pardellas Velay, Rosamna (2016): "O sumidoiro da memoria, que o mesmo serve para lembrar que para esquecer. Reflexiones sobre la memoria en los cuentos de Manuel Rivas", Olivar 16/24, https:/www. olivar.fahce.unlp.edu.ar/article/view/Olivar2015v16n24a03/7327.

Peris, Àlvar (2010): "Internet e identidad nacional: Estado, dominios y comunidades virtuales", IC Revista Científica de Información y Comunicación 7, pp. 221-253, https://idus.us.es/handle/11441/18299.

Piñeiro, Ramón (2001): Filosofía da saudade. A Coruña: La Voz de Galicia. (2007): “Un poema da emigración”, en R. Piñeiro, Olladas no futuro. Vigo: Galaxia, pp. 63-65.

Rivas, Manuel (2001): "Galicia contada a un extraterrestre”. El País (Madrid) 14/10/2001.

(2003): Do descoñecido ao descoñecido: obra poética (1980-2003). A Coruña: Espiral Maior.

(2004): Unha espía no Reino de Galicia. Vigo: Xerais.

(2016): “Argentina y Galicia son como un país simbiótico" (entrevista de Carlos E. Cué e Mar Centenera), El País (Madrid) 28/04/2016, https://elpais.com/cultura/2016/04/28/actualidad/1461866539_708616. html [consulta: 12/08/2018].

Rodríguez Fontela, Ma Ángeles (2014): "Retórica publicitaria e identidade cultural. Estudio comparativo de los spots de Gadis y Campofrío", Tropelías. Revista de Teoría de la Literatura y Literatura comparada 22, pp. 129-145.

Seoane, Luís (2002): Fardel de eisilado. A Coruña: La Voz de Galicia.

(2016): "Epistolario", en Epistolarios. Santiago de Compostela: Consello da Cultura Galega, http:// consellodacultura.gal/fondos_documentais/epistolarios/epistolario.php?epistolario=1651 [consulta: 25/ 03/2018].

Torres Queiruga, Andrés (1980): Nova aproximación a unha Filosofía da Saudade. Discurso de Recepción na Real Academia Galega. A Coruña: Real Academia Galega, http://publicacions.academia.gal/index. $\mathrm{php} / \mathrm{rag} / \mathrm{catalog} / \mathrm{book} / 85$.

Valente, José Ángel (2008): Obras completas. Vol. II. Ensayos. Barcelona: Galaxia Gutenberg, Círculo de Lectores.

(2017): Cántigas de alén. Ourense: Ouvirmos. 
Vasconcelos, Carolina Michaëlis de (2016): A saudade portuguesa. Divagações filológicas e literarhistóricas em volta de Inês de Castro e do cantar velho "Saudade minha, quando te veria?". Delhi: Facsimile Publisher.

Vaz, Jorge (2012): "Lo humano en la obra de Manuel Rivas: un puente entre lo gallego y lo universal", en O. Rodríguez-González, L. Carballo Piñeiro e B. Baltrusch (coords.), Novas achegas ao estudo da cultura galega II. A Coruña: Universidade da Coruña, pp. 203-214, https://ruc.udc.es/dspace/ handle/2183/13264. 